\title{
LOS ALBORES DE LA HISTORIOGRAFÍA GRIEGA. DIALÉCTICA ENTRE MITO E HISTORIA
}

The rise of Greek Historiography takes place between the end of the vi century B. C. and the early years of the v century B. C. The logographi in search of the lo-

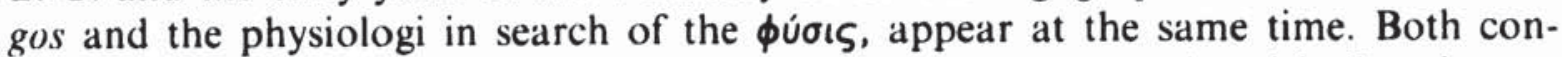
front a mythical tradition and try to discover the coherent and verisimilar element in myth. Historiography looks for the historicity of the real facts hidden inside myth. The result is a dialectic struggle between myth and history.

1. Los distintos géneros literarios, de que hoy hablamos, nacieron en Grecia. Pero no nacieron a la vez como generación espontánea. Fueron surgiendo conforme a las exigencias que las circunstancias imponían. De aquí que un género literario en Grecia, al menos hasta la época helenística, siempre hincaba sus raices en la realidad histórica del momento y en su complejidad. La formalización de los mismos constituyó una horma que arropaba su contenido, ya político, ya religioso, ya histórico, ya agónico. Primero la épica, luego la lírica, después la filosofia y la historiografia casi al tiempo, así como la tragedia, la comedia y la oratoria.

2. Pero tales géneros no sólo no surgen a la vez. Tampoco cada uno de ellos brota claro y distinto como un fogonazo en la oscuridad. Más bien como un lento despertar que paso a paso se va conformando hasta llegar a su madurez. Es lo que acontece en el género historiográfi$\mathrm{co}{ }^{\text {. }}$ Este despertar tiene lugar a finales del siglo vi y principios del $\mathrm{v}$ y

1 Sobre este aspecto, se consideran fundamentales los siguientes trabajos: Felix Jacoby, "Ueber die Entwicklung der griechischen Historiographie", en Abhandlungen zur griechischen Geschichtschreibung, ed. H. Bloch, Leiden 1956, pp. 16-64. Este trabajo discutible fue publicado en Klio 9, 1909, pp. 8-123. E. Schwartz, «Ueber das Verhältnis der Hellenen zur Geschichte», Logos 9, 1920, reimpr. en Gesammelte Schriften, Berlin, 1938, I, p. 58 ss. J. B. Bury, The Ancient Greek Historians, Nueva York, 1909. Lionel Pearson, Early Jonian Historians, Oxford 1939; Ch. William Fornara, The Nature of History in Ancient Greece and Rome, Berkeley 1973; K. von Fritz, Die griechische Geschichschreibung, vol. I, Berlín 1967. K. Latte, «Die Anfänge 
en la inquieta región de la Jonia asiática. Aquí y en esa época se produce la preocupación por buscar la sustantividad de la realidad material: se busca como principio y fundamento la naturaleza, la $\phi \dot{\sigma o \iota s}$, que sus-

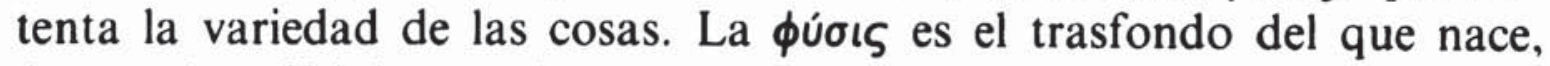
фúetal, lo múltiple. Fue la aventura de los Presocráticos. Los Romanos la tradujeron por natura, de nascere, nacer, con plena captación de su mensaje filosófico. Pero en paralelo con esta investigación, se busca asimismo la sustantividad de la dimensión humana. Y como más tarde recordará Isócrates ${ }^{2}$, la tradición no pudo haber recordado los acontecimientos de un pasado lejano a no ser que éstos hubieran tenido la capacidad de resistir el asalto del tiempo. Para un griego fue una constante que ninguna cosa procede de la nada, por lo que si se ha conservado el recuerdo de hechos pasados, éstos tuvieron alguna realidad.

3. Ahora bien, esa sustantividad, como fundamento en el pasado, se buscó unas veces en las genealogías ${ }^{3}$, en la secuencia de héroes desde los tiempos míticos, secuencia que sostiene la continuidad del yévos. Un representante máximo de este tipo de escritos fue Hecateo de Mileto; otras, en las fundaciones de ciudades con sus rasgos más sobresalientes de tinte etnográfico. En este contexto deben citarse la fundación de $\mathrm{Mi}$ -

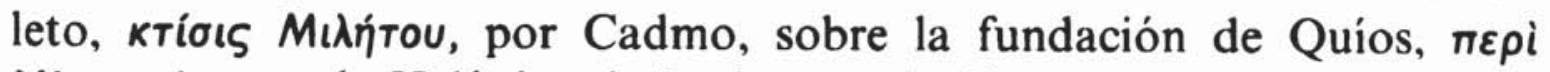

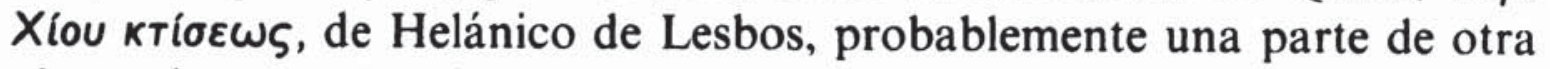

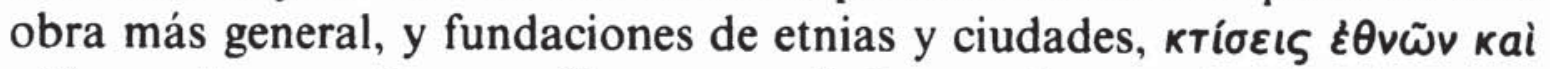
$\pi \delta ́ \lambda \varepsilon \omega v$. Son escritos que llevan por título con frecuencia el país a que se refieren: los Lidiaca de Janto de Lidia, al estilo de los Persica, de Dionisio de Mileto. Son autores anteriores en general a Heródoto y Tucídides.

4. Dionisio de Halicarnaso ${ }^{4}$, con ocasión de su ensayo sobre Tucidides, refleja la atmósfera historiográfica de estos escritores. Tras enumerar muchísimos nombres, comenta: «estos autores en la elección de sus temas usaron el mismo principio y propósito, y no se diferencian

der griechischen Geschichtschreibungs", Histoire et historiens dans l'antiquité, Vandoeuvres-Ginebra 1958, p. 1 ss. W. Schadewaldt, "Die Anfänge der Geschichtschreibung bei den Griechen", Antike 10, 1934, p. 144 ss.

Paneg. 69. Sobre esta cuestión, cf. Fornara, op. cit., p. 4 ss. Pearson, op. cit., p. 25 ss., que estudian otros autores en la misma línea.

3 Los fragmentos se encuentran en Jacoby, Die Fragmente der griechischen Historiker, Berlín-Leiden 1923-1958. Los textos están dispuestos de la siguiente manera: I. Historia del pasado legendario, genealogía e historiografia. II. Historia General y Contemporánea, Cronografia. III. Historia de los pueblos y ciudades, Etnografia y Crónicas. Los textos llegan hasta el número 856 , pero el comentario se interrumpe en el 107. Asimismo, sigue siendo útil C. y T. Müller, Fragmenta Historicum Graecorum, París, Didot, 1841-1870.

${ }^{4} T h . \mathrm{V}$. 
mucho en habilidad. Unos escribieron historias griegas, otros bárbaras, pero sin conexión mutua; por el contrario, divididas por etnias y ciudades, y publicadas por separado. Tenían una única y misma finalidad: llevar al conocimiento general de todos los hombres las tradiciones del pasado tal como las recibieron y los recuerdos por etnias y ciudades, sin añadir ni quitar nada. Estas narraciones ${ }^{5}$ contienen algunos mitos en los que desde antiguo se creía, y que hombres de hoy consideran infantiles».

5. Dionisio acierta cuando describe los temas, el propósito y el método de estos autores. Pero no es del todo verdad el afirmar que transmiten las tradiciones sin quitar ni añadir nada. Estos autores buscan la

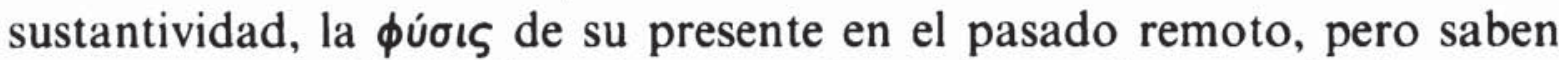
que ese pasado les ha llegado arropado en la poesía y en el mito y saben también, como hoy nosotros, que ese pasado encierra y refleja acontecimientos reales que en verdad sucedieron. $\mathrm{Y}$ obsérvese que no digo que tales tradiciones sean historia, sino que esconden acontecimientos reales. El cometido de estos logógrafos ${ }^{6}$ fue hacer congruente el pasado mítico con el presente con perspectiva casi, casi de historicidad y unas veces expurgando y otras añadiendo. No tiene en esto razón Dionisio de Halicarnaso.

6. Mas, ¿cómo se consiguió esta congruencia entre pasado y presente? Porque ésa es la cuestión y el tema de este trabajo. Y su desarrollo nos ocupará cuatro etapas:

a) Una primera en la que precisaremos qué aspectos del mito, esa realidad huidiza, son relevantes para la historiografia;

b) Una segunda en la que exponemos por qué el mito, que va a ser fundamento de la historiografia y si bien encierra contenidos reales, no es historicidad;

c) Una tercera etapa donde enumeramos los factores más significativos que dieron lugar al nacimiento de la historiografia;

d) Por último, cómo la historiografia provoca la historicidad del mundo mítico, aunque con más o menos fortuna.

7. Es una constante que la teoría y la crítica se producen después de aquello sobre lo que se teoriza y critica. Se contempla - que eso significa teoría - y se cierne - que eso significa crítica - cuando se tiene delante el objeto y se puede separar el trigo de la paja. Aristóteles teori-

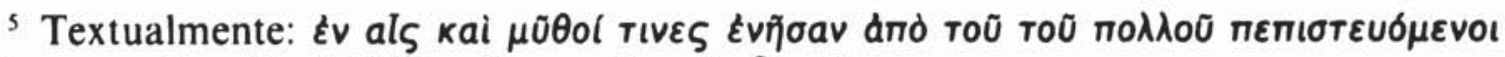

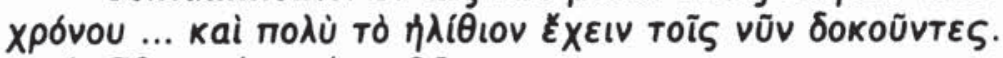

${ }^{6}$ Cf. aquí parágr. 25. 
zó y criticó la tragedia griega cuando ésta hubo alcanzado su naturale$\mathrm{za}^{7}$. Lo mismo acontece con la distinción entre mito e historia. Hasta el punto que incluso la palabra historia, íropía, con el contenido de obra sobre las acciones humanas, tal como aparece, por ejemplo, en

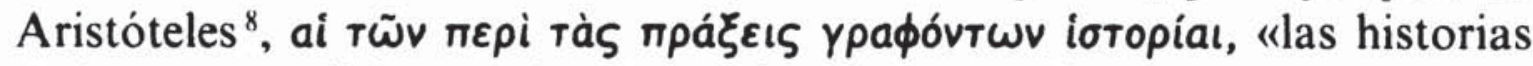
de los que escribieron sobre las acciones», es tardia. Quizá podría aceptarse que ya en Heródoto ${ }^{9}$ este vocablo significa historia en su sentido propio. Tras una larga enumeración de las tropas de Jerjes, ya en Tracia, se dice lo siguiente: "al frente de estas tropas "de mar" y de las formadas de tierra, estaban jefes indígenas, de los cuales no hago mención porque la narración de la historia no me obliga a ello" ${ }^{10}$.

8. Pero la realidad es que la distinción entre mito e historia como dimensiones distintas y de forma teórica procede de época helenística y tardía. Ya en Cicerón ", aparte las narraciones de tipo forense, encontramos la distinción entre fabula, argumentum e historia ${ }^{12}$. Y define cada uno de los términos: fabula est in qua nec uerae nec ueri similes res continentur; historia est gesta res, ab aetatis nostrae memoria remota; argumentum est ficta res, quae tamen fieri potuit. Ahora bien, Sexto Empirico ${ }^{13}$ responde a esta terminología latina con $\mu \tilde{\theta} \theta$ os para fabula, con

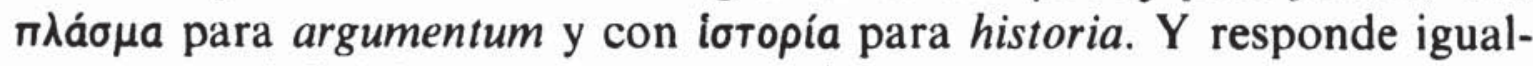
mente con definiciones semejantes: "historia es la exposición de hechos

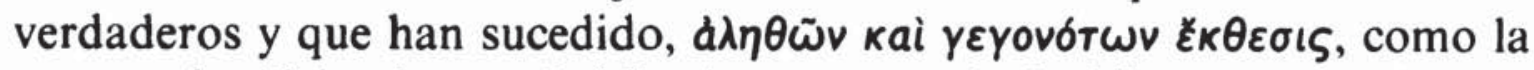
muerte de Alejandro en Babilonia envenenado insidiosamente; $\pi \lambda a ́ \sigma \mu a$, argumento, es la narración de hechos que no han sucedido pero que se

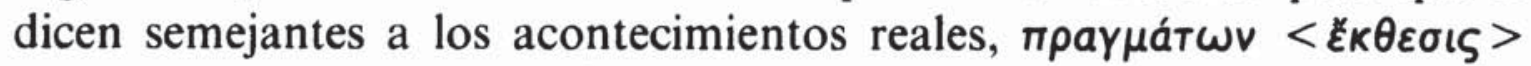

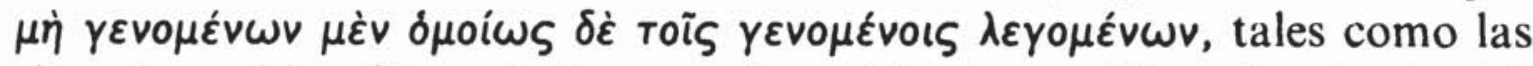
situaciones hipotéticas de la comedia y del mimo; $\mu \tilde{0} \theta_{\circ}$, fabula, significa la narración de hechos que no han sucedido y que son falsos ${ }^{14}$, $\pi \rho a \gamma$ -

7 Poet. 4, 49 a 15.

8 Rh. 1360 a 37.

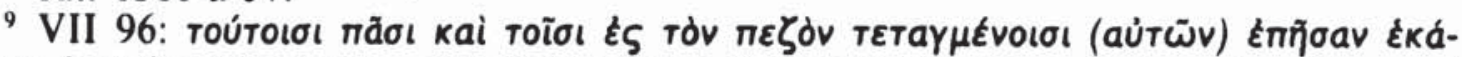

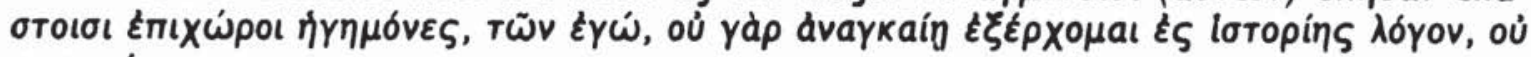

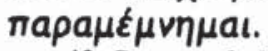

${ }^{10} \mathrm{La}$ palabra sigue, no obstante, significando investigación. Plat., Phd. 96a: $\eta$

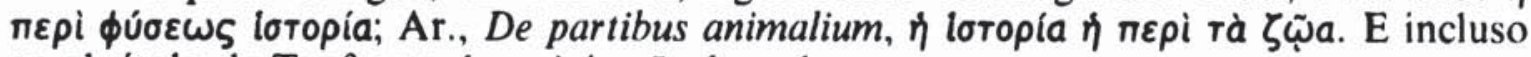

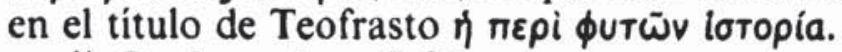
I 12 ss.

"De Inuentione, I 27 y, por supuesto, como un eco, en el autor Ad Herennium

${ }^{12}$ Los detalles y los distintos textos en K. Barwick, "Die Gliederung der narratio in der rhetorischen Theorie und ihre Bedeutung für die Geschichte des antiken Romans», Hermes 63, 1928, pp. 261-287.

13 Adu. Gramm. 263 ss.

${ }^{14}$ Cf. K. Barwick, art. cit., p. 270. 


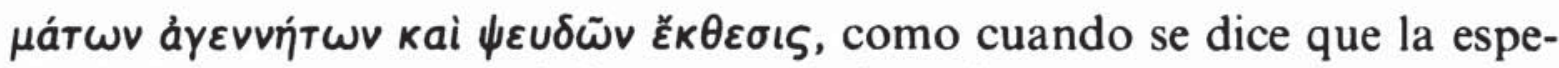
cie de la serpiente nace de la sangre de los Titanes.

9. El ejemplo que se aduce de mito llama la atención. Es un ejemplo que la mente humana se resiste a aceptar; de aquí que con frecuencia encontremos la apostilla, se necesita de una "fe indiscutible", áva $\mu$ -

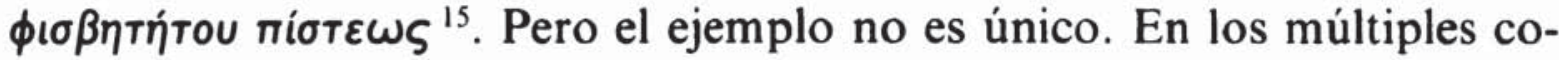
mentarios y escolios los ejemplos son del mismo tenor: Dafne que se convierte en árbol ${ }^{16}$; los Cíclopes y los Centauros ${ }^{17}$. Todos ejemplos increíbles y maravillosos: son narraciones cuyo contenido no ha sucedido. Por tanto quedan fuera de la historia, al igual que las narraciones de la comedia que, aunque sus contenidos son verosímiles y que pueden suceder, no han sucedido.

10. Y claro es, este aspecto del mito no es que no sea historia, lo que va de suyo, sino que le es indiferente a la historia y no es posible dialéctica alguna. La dialéctica implica que dos realidades que rivalizan tienen algo de común sobre lo que se dialoga. Los críticos exponen una situación polar: lo no sucedido y lo imposible por naturaleza que suceda frente a lo sucedido propio de la historia. Pero los historiadores expurgaron mucho más lo maravilloso del mito, no ya lo imposible, sino lo incongruente.

11. Pero entonces, ¿cuál es el mito que rivaliza con la historiografia? Se habrá observado en la clasificación mencionada que se habla de comedia, de mimo, de historia, de fábula en sentido de lo fabuloso, pero no se habla de la épica ni de su epígono la tragedia. La razón es clara: la épica, el mito homérico y su secuela en los Cantos Ciprios y en el mito trágico, no es ajeno a la historia, aunque no sea historicidad ${ }^{18}$. Tucídides mismo nos habla de Helen, el hijo de Deucalión, de Minos y su talasocracia, de Aquiles, de Pélope, de Tindáreo, de Atreo, de Agamenón y demás personajes ${ }^{19}$. Luego se me permitirá que sitúe la dialéctica entre mito e historiografia en el mito épico, en el mundo mitificado por Homero y en el ciclo épico y ello porque tiene algo de historia, ese rasgo común que permite que el mito épico se haga historia. Pero la ob-

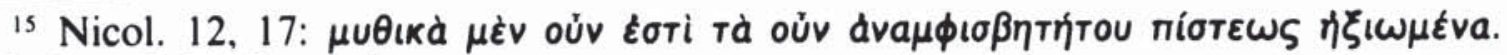
Isid. Orig. I 44, 5: quod contra naturam sunt.

${ }_{16}$ Mart. Cap. 486, 16: ut Daphnem in arborem uersam.

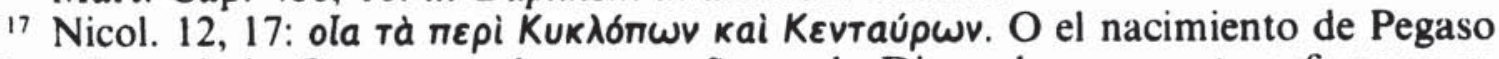
de la cabeza de la Gorgona o los compañeros de Diomedes que se transforman en pájaros marinos.

${ }_{18}$ Es doctrina común. Cf. Fornara, op. cit., p. 9. El propio Eforo se hace eco de esta realidad; cf. Jacoby, F. Gr. Hist. 70 F 9.

${ }_{19} \mathrm{Th}$ I $1-22$. 
servación de que el mito épico tiene algo de historia pero no es historicidad nos introduce ya en la segunda etapa de nuestro análisis.

12. En efecto, hoy dia, tras las excavaciones realizadas en los distintos lugares que precisamente señalan los poemas homéricos, no tenemos dudas sobre el hecho de que tales poemas filtran un trasfondo de realidad. La guerra de Troya tuvo como fermento un hecho histórico e incluso su momento cronológico puede situarse con bastante exactitud hacia el 1200 a. C. El propio Heródoto ${ }^{20}$ ya vislumbró esta cronología. Es más, los hallazgos arqueológicos y las lecturas del dialecto micénico, así como textos hetitas, proporcionan la posibilidad de explicar los distintos objetos descritos por Homero, tales como la variedad de cascos, de carros, de escudos ${ }^{21}$, etc., y, por si fuera poco, tras la brillante tesis de Nilsson ${ }^{22}$, la posibilidad de consolidar realmente la adscripción de los distintos jefes griegos a sus respectivos reinos. Desde una perspectiva científica actual, los poemas homéricos son la poetización de un mundo real e histórico. Todo ello es ya sabido.

13. Pero ésa no es la cuestión relevante. La cuestión radica en que los poemas, como tales en su unidad, se conocen hacia finales del s. VIII a. C. Homero tiene un presente, una realidad circundante que no es la que se canta en sus poemas. La realidad de sus poemas es la de un pasado remoto y brillante, separado de su presente por la ruptura y el vacío de un largo período. Los griegos del s. vill y vil admiran muros enormes y cúpulas, como la de Atreo, que parecen sobrepasar la capacidad humana. Mas son obras no de hombres, sino de seres extraordinarios, son muros ciclópeos. El pasado que recuerda tales monumentos es un pasado que queda al margen de la esfera humana, no es su pasado, sino un pasado heroico que se aisló en sí mismo ${ }^{23}$. Como se ha observado, fueron los dorios los que provocaron este aislamiento al romper, mediante la destrucción y expulsión, los eslabones que unian y enlazaban con la época micénica ${ }^{24}$. Aislamiento de un mundo que, sumido en

${ }^{20} \mathrm{Hdt}$. II 145,2. Los estudios sobre este punto son muy numerosos. Desde un punto de vista teórico y de su relación con la prehistoria griega, $\mathrm{cf}$. W. Burkert, Preistoria. Epoca Minoico-Micenea, trad. it. por P. Pavanini, Milán 1984, y su casi exhaustiva bibliografia. Interesante también M. Sakellariou, Peuples préhelléniques d'origine indoeuropéenne, Atenas, 1977.

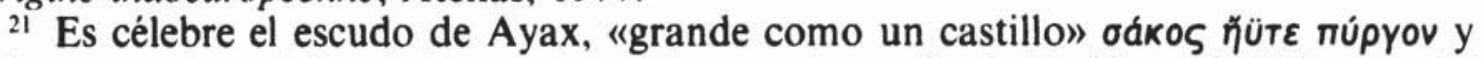

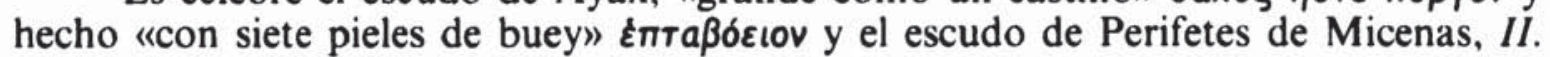

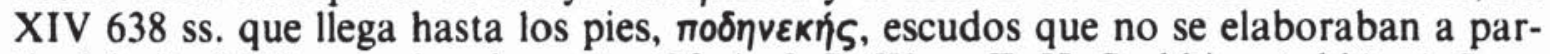
tir del año 1350 aproximadamente. Cf. A. J. B. Wace-F. H. Stubbing (edd.), A Companion to Homer, Londres 1962.

${ }_{22}$ M. P. Nilsson, Geschichte der griechischen Religion, Munich 1967, p. 256 ss.

${ }^{23}$ Este punto de vista está bien analizado por B. Snell, Las fuentes del pensamiento europeo, Madrid 1965, p. 215 ss.

${ }^{24}$ W. Schadewaldt, art. cit., p. 148 ss. 
la indeterminación del recuerdo, se tornó propicio para ser configurado poéticamente: la mitología heroica griega es fruto, en sus fundamentos, de un hecho histórico: la ruptura por los dorios con el mundo micénico.

14. Este aislamiento, consecuentemente, rompe, asimismo, las cadenas del tiempo y del lugar y permite el vuelo creador de la imaginación. La épica homérica plasma y dibuja un cuadro nuevo de la guerra de Troya. La Iliada supone conocida la guerra de Troya, cuyos principios y consecuencias no tiene en cuenta. Su novedad consiste en elegir un motivo en torno al que giran los demás acontecimientos: Agamenón había desobedecido la petición del sacerdote de Apolo, Crises, de devolver a su hija Criseida. Apolo, en consecuencia, envió la peste a las huestes griegas, lo que origina la rivalidad entre Agamenón y Aquiles. Éste pide a su madre Tetis que suplique a Zeus para que conceda la victoria a los Troyanos mientras que él permanece enojado en su tienda. Todo lo demás es un desarrollo de esta motivación poética.

15. Pero ya tenemos un mundo, no ya lejano y aislado, sino un mundo arcano, donde se mezclan dioses y hombres y donde las peripecias de las acciones humanas dependen de los dioses. Es Apolo quien envía la peste, Tetis la que suplica a Zeus, y es éste el que conduce a su gusto la guerra. Se crea un mundo que gira en una órbita propia e independiente: la oposición entre dioses y hombres por la que los dioses son grandes a costa de los hombres y los hombres son grandes a costa de los dioses, no tiene nada que ver con un pretérito y un presente. Ese mundo de dioses y hombres no es un pretérito, no es un presente que se ha ido, es un mundo fuera del tiempo.

16. Y es claro que ese mundo arcano, aislado en la nebulosa del recuerdo y poetizado, no explica por sí el presente, la situación histórica presente, por la sencilla razón de que la situación presente no es un despliegue, una abertura de ese pasado, aunque éste esconda hechos reales. Los griegos contemporáneos de Homero no veían intervenir a los dioses en sus asuntos $\mathrm{y}$, si en algún momento se dice que intervineron, sin duda podian pensar que ese mundo no iba con ellos. Es un mundo que no entra en su historia. Porque la historicidad consiste precisamente en tener conciencia de que lo que ahora se es, tiene un fundamento, no sólo explicativo, sino incluso ontológico en momentos anteriores. Cuando se dice que el hombre es historia y no naturaleza quiere decirse que es un ser abierto a posibilidades, pero no desde el vacío, sino desde el anclaje de sus propias acciones y realizaciones.

17. En este sentido, el mundo homérico no proporciona anclaje alguno. Pero ello no significa que los poemas homéricos no tuvieran influencia en la cultura posterior. Nada ha influido tanto y tan intensa- 
mente, mas no desde una perspectiva de contenido histórico. Los héroes y dioses y sus acciones no explican el presente humano. Sin embargo, esos seres y acciones se convirtieron en arquetipos, en paradigmas por los que comprendemos mejor nuestros propios actos y los ideales a los que debemos tender, fenómeno éste que aprovechó al máximo la tragedia griega: lo que aconteció a Agamenón en la narración homérica, Esquilo lo hizo símbolo de la grandeza y miseria humanas. Y fijémonos bien: lo arquetípico y paradigmático es característico del mito.

18. Pero bien se ve que estamos en un plano diferente: el mito homérico que tiene su fundación en hechos reales, en cuanto expresión de un mundo aislado, arcano y ajeno a lo más propiamente humano, no constituye el pretérito de un presente. No tiene historicidad ni despierta conciencia histórica. Pero el mito homérico, como fenómeno formal y paradigmático, se convirtió en categoría, en acusación y valoración de situaciones presentes: en el primer caso se trata de un enfoque ontológico, de causalidad real; en el segundo, de un enfoque axiológico.

19. Y la verdad es que, desde esta última perspectiva, la épica homérica contiene, en germen por supuesto, aspectos que se desarrollan posteriormente en el quehacer historiográfico y en la literatura clásica posterior. $\mathrm{Y}$ entramos en la tercera etapa. Con brevedad enumero los aspectos que a mí me parecen más importantes. Se encuentra ya la idea de una comunidad helénica que se enfrenta a un pueblo de Asia Menor. Esta comunidad no recibe, como dice Tucídides ${ }^{25}$, todavía un nombre común, pero representa, sin duda, una conciencia de estirpe homogénea. Esta oposición entre griegos y no-griegos, tan interesante en el núcleo de la historiografia de Heródoto, estaba ya reflejada en la Etiópi$d a^{26}$, en la que Aquiles lucha ya abiertamente contra pueblos bárbaros en tanto que enemigos de los griegos y aliados de los troyanos: recuérdese Mennón, Pentesilea y las Amazonas.

20. Otro aspecto es el deseo por volver a su pasado, la nostalgia por el regreso a su hogar: Ulises representa esta noción de manera significativa. Todo su esfuerzo y peripecia se encamina hacia la recuperación de la patria, e igualmente su esposa, que recurre al engaño con la esperanza de volver a su estado originario. La épica poshomérica desarrollará esta noción nostálgica en los cantos conocidos como Nostoi.

21. Asimismo, la propia Ilíada alude a acontecimientos anteriores a los que está narrando: por dos veces Diomedes ${ }^{27}$ recuerda que su pa-

${ }^{25} \mathrm{Th}$ I 3,1.

${ }^{26}$ Una excelente discusión sobre este aspecto, U. Hölsher, Gnomon 27, 1955, p. 392 ss.

${ }^{27}$ Il. IV 370 y V 800. 
dre Tideo había sido uno de los héroes en la vana lucha de los Siete contra Tebas pero, a decir de Esténelo, compañero de aquél, fueron los epígonos los que lograron doblegar a Tebas. Es este episodio, entre otros como podrían ser el recuerdo de héroes anteriores por Néstor ${ }^{28} \mathrm{o}$ la historia de Meleagro, un buen ejemplo de penetración de sentido cronológico e histórico en medio de la leyenda ${ }^{29}$. Y no me resisto a creer, con E. Schwartz ${ }^{30}$, que los Cantos Ciprios, que cantaban los episodios precedentes a la guerra de Troya, representan ya la "historización» de la épica. Aquí Zeus decreta la guerra de Troya porque ve a la Tierra superpoblada y agobiada y trama el juicio de París, el rapto de Helena y los hechos que tuvieron lugar en Aulide. El carácter descriptivo y cronológico es importante.

22. Son estos aspectos los que empujan a los diversos estudiosos a atribuir al mito una forma primeriza de historia, una "Urform der Geschichte». Y quizá ello sea verdad. Pero tales aspectos no son factores suficientes para explicar el nacimiento de la historiografia. A mi parecer, son tres los factores fundamentales.

23. En primer lugar, la propia realidad histórica. En el s. vi surge una realidad que necesariamente atrae la atención de los griegos. Se trata del auge y amenaza del Imperio Persa. Es una realidad que se ve y se toca, y que merece ser historiada. Los griegos la conocen y el Imperio Persa gusta de tener a su servicio hombres helenos. No sorprende que los primeros historiadores eligieran como campo propio la historia de Persia y su influencia. Hecateo de Mileto recorrió Persia, entre otros lugares. Carón de Lámpsaco escribió una historia de Persia, y lo mismo Dionisio de Mileto. Esquílax de Carianda fue empleado por Dario para que le acompañara en su exploración del río Indo, cuyos resultados publicó. El horizonte ya no es un pasado lejano y envuelto en la niebla del mito, sino un horizonte circundante, las dos cualidades que Heródoto pone como imprescindibles para hacer historia, ö $\psi \iota \varsigma$ y ákón, el ver y el oír se pudieron poner en práctica entonces por primera vez ${ }^{31}$.

24. El segundo factor que alborea también en Jonia, con los mencionados historiadores, es el espíritu crítico y racionalista frente a la tradición mítica. De manera directa, Jenófanes de Colofón, según Diógenes Laercio ${ }^{32}$, «escribió elegías y yambos contra Hesiodo y Homero,

28 Il. XI 670 y VII 132.

${ }^{29}$ II. IX 524.

30) Art. cit., p. 144 ss.

${ }^{31} \mathrm{Cf}$. aqui parágr. 32. Con más precisión, Hdt. II 45, 7 y VII 152,11.

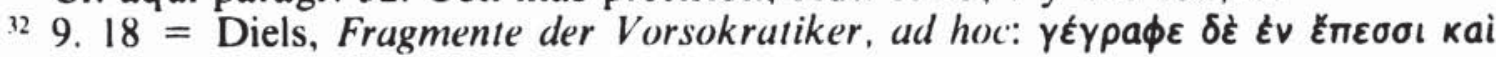

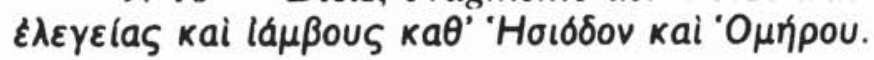


censurándoles lo que dijeron sobre los dioses». Y son conocidos sus versos contra la naturaleza antropomórfica de los dioses de la religión convencional. Este espiritu crítico que, en el plano de la filosofia, según hemos dicho ya, busca la explicación de la realidad mediante la razón, en el historiográfico busca la congruencia y la verosimilitud de lo narrado. La creencia en lo transmitido exige una cierta racionalidad y es en este contexto en el que debe insertarse el nacimiento y correcciones de literatura genealógica, literatura que si bien se debió al deseo de las'familias aristocráticas por conectar con su pasado heroico, pronto se vio afectada por la criba que impuso el racionalismo de la época. En esto también fue pionero Hecateo, seguido de Ferécides de Leros, Acusilao y otros.

25. Por último, y quizá el factor más importante, fue la aparición de la prosa frente a la poesía. Ello fue casi de necesidad. El dar cuenta de noticias, de viajes, de nombres de pueblos y descripciones, exigía una expresión diferente a la que la poesía podía ofrecer. La objetividad referencial no cuadra bien con el personalismo y subjetividad de la poesía. $\mathrm{Y}$ no es extraño que el nombre genérico que reciben estos primeros historiadores sea el de logógrafos, escritores en prosa, por contraste con el epos. No obstante, esta traducción no refleja la dimensión exacta de su aparición, sino más bien un aspecto formal. No refleja la función y cometido del término logos, que no es sólo narración, sino narración de algo que se ha recogido, $\lambda \dot{\varepsilon} \gamma \varepsilon \iota v$, y de algo que ha sido puesto en orden

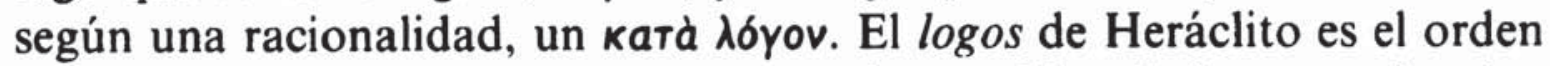
inserto en las cosas; el logos en estos primeros historiadores es el orden de lo que veían, leían y oían. Logógrafo, por tanto, es un escritor en prosa que pone en orden lo que ha visto y oído, orden enmarcado en el espacio y el tiempo ${ }^{33}$.

26. Así pues, realidad circundante, espíritu crítico y racionalista y expresión en prosa, propia de la objetividad referencial, constituyen tres factores fundamentales sin duda en el nacimiento de la historiografia. Y cualquiera podría pensar que con estas flechas en su carcaj la historiografia heria de muerte al mito tradicional, negándole toda referencia a hechos y acontecimientos. La cuestión no es tan simple, sin embargo.

27. Y adelantaré, y entramos en la última etapa, que la historiografia no sólo no rechazó el mito en su totalidad, sino que por el contrario incluso intentó incorporarlo como fenómeno histórico. El análisis

${ }^{33} \mathrm{Y}$ debo decir que, desde esta perspectiva, ello no implica oposición radical con el mito. Y la prueba la encuentro en el propio Hecateo, fr. 13. Jacoby, op. cit.: 'Eka-

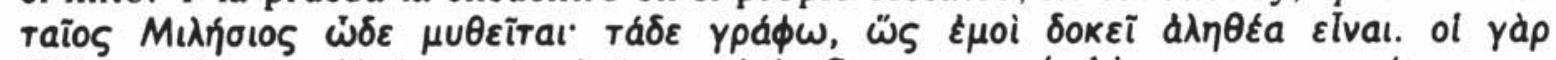

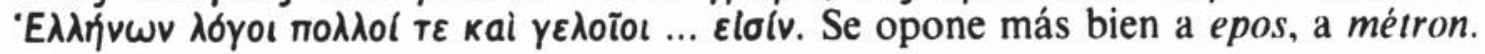


de este apartado lo centramos en Heródoto y Tucídides. Y debo recordar que a la historiografía sólo le importó el mito heroico, el realizado por hombres, aunque sean héroes. Los mitos referidos a extravagancias increíbles no entran en la consideración histórica. Es a estos mitos heroicos a los que se aplica el nuevo bagaje crítico de la historiografia, unas veces para armonizarlos con lo verosímil y otras para arrancarles historicidad.

28. Esta segunda función, arrancarles historicidad, la encontramos de manera tosca en Heródoto, pero con finura intelectual en Tucídides. Sin embargo, la primera, la armonización, ya se observa con frecuencia en los llamados logógrafos. Sirva un ejemplo del más representativo, de Hecateo ${ }^{34}$, tomado de las Genealogias, referido a Heracles y a los Heraclidas, y que además atañe a Homero. El ejemplo alude a la leyenda de que Heracles sacó por el cabo Ténaro el perro del Hades, aunque no hay a través de la cueva un camino que lleve a bajo tierra. "Hecateo de Mileto - cito textualmente - encontró una explicación verosímil - $\lambda \delta$ yov عіко́та - suponiendo que en Ténaro se crió una terrible serpiente llamada "perro de Hades" porque, el que por ella fuera mordido, perecería inmediatamente por la fuerza del veneno. Esta serpiente sería la que Heracles llevó a Euristeo".

29. Estas son las narraciones ridículas de que habla Hecateo. Son aspectos extraordinarios y no dignos de crédito. $\mathrm{Y}$ no se trata de interpretaciones alegóricas. La interpretación alegórica acepta el texto, sólo que busca un mensaje distinto. El texto habla de otra manera, á $\lambda \lambda_{0}$ áyo$\rho \varepsilon u ́ \varepsilon ı$. Se trata, por el contrario, de encontrar la verosimilitud de la tradición sin que ello quiera decir que tales tradiciones sean irreales y no verdaderas en su totalidad. Es irreal aquella arista del mito que contradice la verosimilitud ${ }^{35}$.

30. Esta práctica de buscar la congruencia del mito sería una constante de la historiografia. En Heródoto encontramos por dos veces la palabra «mito». Una ocasión es aquélla en que alude a las explicaciones que se han dado respecto a las crecidas del Nilo en verano. Después de rechazar la explicación de los vientos etesios ${ }^{36}$, presenta una segunda ${ }^{37}$ y dice: «esta segunda es menos científica y a decir verdad, más maravi-

${ }^{34}$ Hecateo, fr. 27. Jacoby. Tomado de Pausanias, III 215.4.

35 Cf. aquí parágr. 24 y 27.

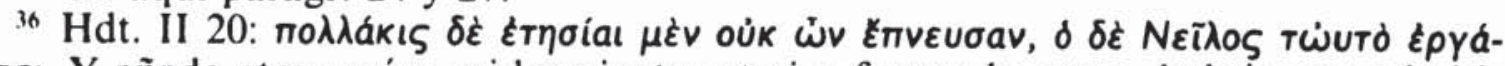
$\zeta \varepsilon т a$. Y añade otra razón: «si los vientos etesios fueran la causa, habría que admitir que los demás ríos que fluyen al encuentro de tales vientos, sufririan el mismo fenómeno que el Nilo").

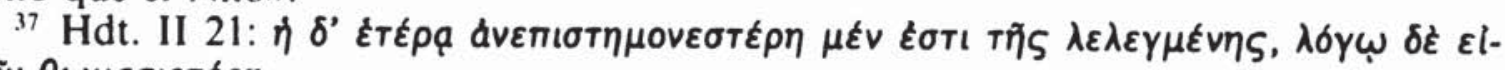

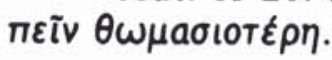


llosa. Pretende explicar el mecanismo de las inundaciones por el hecho de que el Nilo corre desde el Océano, que correría, a su vez, en torno a la tierra entera». Esta explicación la glosa Heródoto así: "esta historia, גóyos, refiere un mito que no puede verse ni probarse. Nunca he visto, por mi parte, un río Océano. Creo que Homero o algún otro poeta anterior ha inventado este nombre y lo ha introducido en su poesía” ${ }^{38}$.

31. La otra ocasión se refiere a Heracles y dice que es un $\mu \tilde{\theta} 0$ o

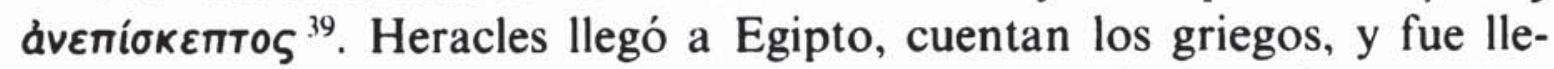
vado a ser sacrificado. Pero, entonces, se enfureció y mató a muchos hombres. Bien se ve, comenta Heródoto, que los griegos desconocen las costumbres egipcias, pues nunca sacrifican seres humanos, y bien se ve que desconocen que Heracles, entonces, era todavía un hombre y no un dios, como para poder hacer frente a tantos hombres ${ }^{40}$.

32. En ambas ocasiones, Heródoto rechaza el «mito" por inconsistente ante los criterios de experiencia y observación. Pero no el mito en sí, sino lo incongruente del mito. Heródoto observa que «debo decir las

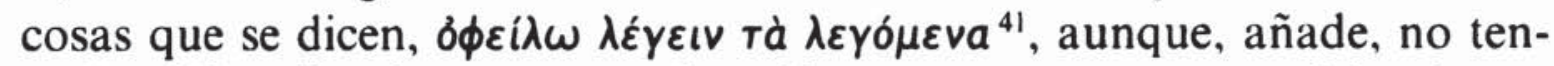
go la obligación de creer en todo". Y, por supuesto, en ese tà $\lambda \varepsilon \gamma o ́ \mu \varepsilon v a$, están incluidas las narraciones míticas. Pero éstas no deben contradecir los criterios de la experiencia y de la observación. Deben tener, nos

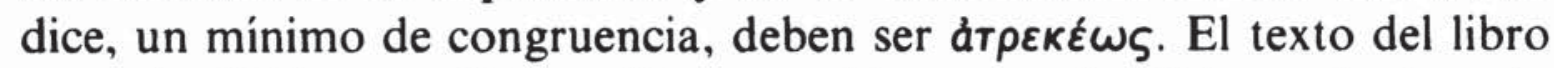
segundo, 2.99, es explícito: «Hasta aquí lo que se ha dicho se ha basado en observación personal, ö $\psi$ เs, en reflexión, $\gamma v \omega \dot{\mu} \mu \eta$, y en la investigación, iбторín. A partir de ahora, voy a narrar lo que los griegos cuentan

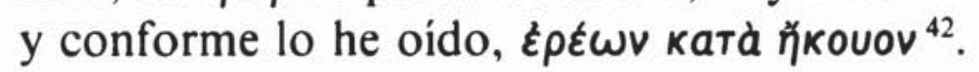

33. Tucídides, por su parte, con esa precisión de que hace gala, toca el corazón del problema. No niega que el período mítico pasado tenga su verdad, como luego veremos, pero está fuera de la historia «lo mítico del mito", тò $\mu \nu \theta \tilde{\omega} \delta \varepsilon \varsigma$. El texto al respecto, como es sabido, se

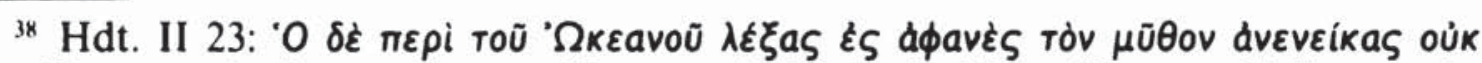

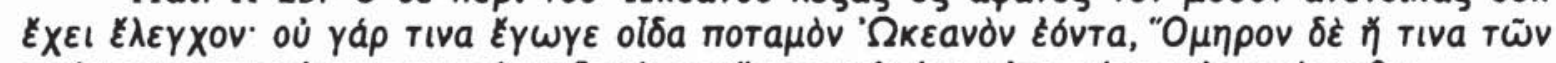

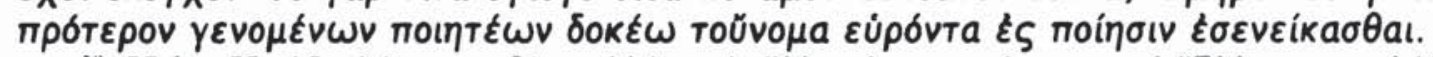

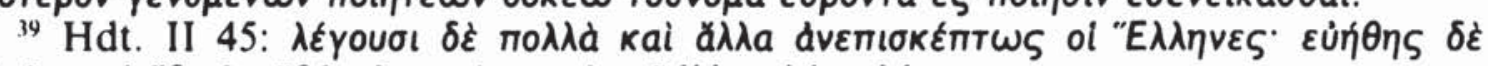

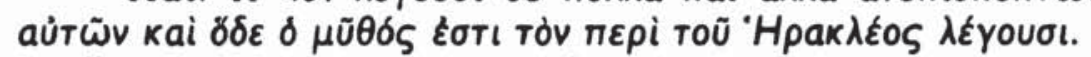

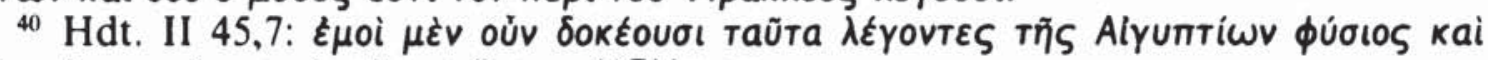

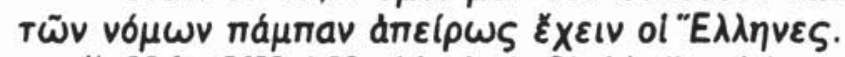

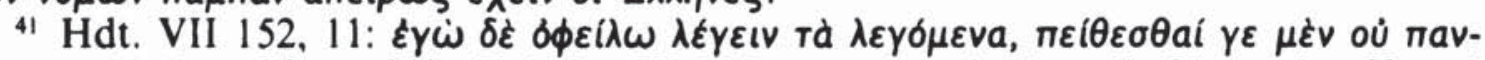

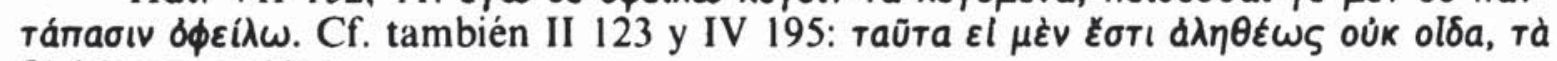

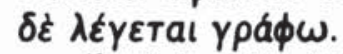

${ }_{42}$ Hdt. VII 152, 7. Además, cf. G. Nenzi, «Il motivo dell' autopsia en la storiografia greca», $S C O 3,1953$, p. 26 ss. 
encuentra al final de su Arqueología ${ }^{43}$ : no se equivocaría el que no diere fe a las cosas que los poetas han contado sobre lo que he narrado,

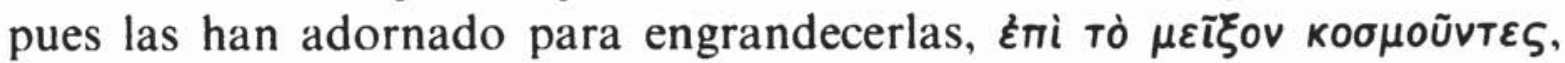
ni a las que los logógrafos han escrito... cosas sin pruebas y llevadas con frecuencia hacia "lo mítico», $\varepsilon \pi i$ rò $\mu \nu \theta \tilde{\omega} \delta \varepsilon \varsigma$ ". Tucídices no niega que el mito encierre algo de verdad. Lo que dice es que a ese fondo real

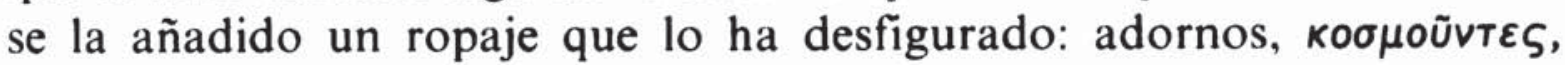
que lo han llevado al terreno de lo maravilloso.

34. Claro que si Heródoto araña pequeñas parcelas maravillosas del mito, el racionalismo de Tucídices cercena gran parte del mismo, hasta exprimir su verdad. Pero Tucídides añade otra razón para cercenar el mito. En el capítulo 22 concreta: «para una lectura pública, quizá

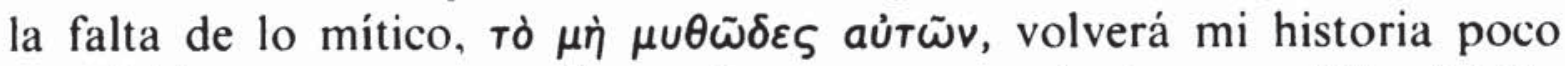
agradable... pero me conformaría con que se la juzgara útil, $\dot{\omega} \phi \varepsilon \lambda_{l}-$ $\mu o v{ }^{44}$. Se introduce un nuevo concepto: el mito, si no conduce a la verdad, es inútil y por tanto no debe formar parte de la historia que debe procurar que sea útil.

35. Esta noción de utilidad de la historiografia tuvo una trascendencia extraordinaria: constituyó el motivo que dio nacimiento a la consideración de que la historia es maestra de la vida, que si bien la frase fue acuñada por Cicerón, la idea parte de Tucídides. Pero dio nacimiento asimismo a la confusión entre el mito épico y heroico con las leyendas que Heródoto ${ }^{45}$ introduce en su Historia, tales como la leyenda de "Candaules y Giges», "Creso», "Polícrates y su anillo" y otros. Esta confusión fue tal que incluso un retórico tardio, Romanus Sofista ${ }^{46}$,

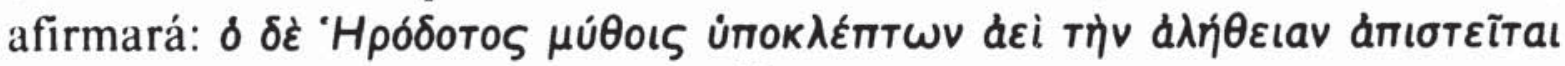

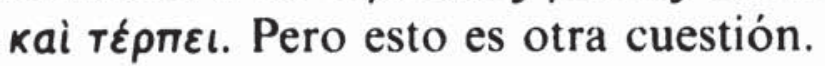

36. Lo importante es el fenómeno de que la historiografia, desde sus comienzos, practica una auténtica purgación del mito épico: en los logógrafos sobre la base de la congruencia; en Heródoto sobre la base de la experiencia de lo visto y oído y en Tucídides sobre la noción de utilidad histórica. Mas es rasgo común a todos el rechazar lo maravillo-

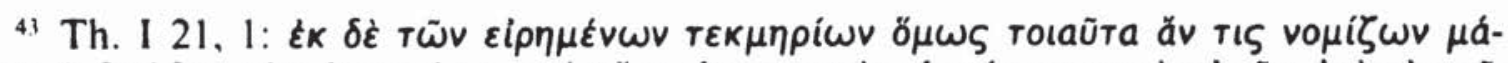

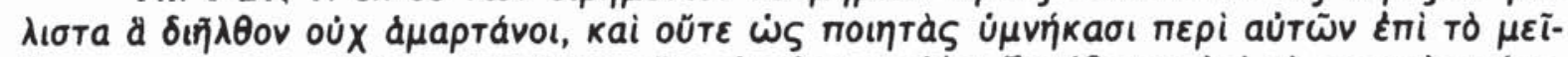

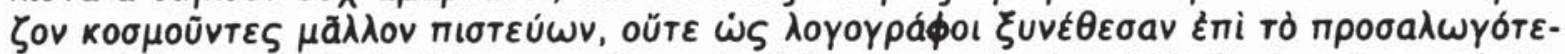

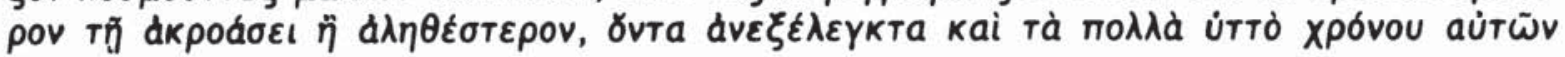
dniorws.

${ }_{44}$ Th. I $22,4$.

${ }^{45}$ Hdt. I 8-12, para Candaules y Giges; para Creso, I 29-33. Para Policrates, III 40-43.

${ }^{46}$ Rhet. Gr. XIII, citado por A. E. Wardman, "Myth in Greek Historiography», Historia 9, 1960, p. 405. 
so e inconsistente del mito tradicional. $\mathrm{Y}$ obsérvese que este rasgo es el que los retóricos antiguos, según expusimos en el primer apartado, consideraban como lo indiferente a la historia. El mito expresa contenidos

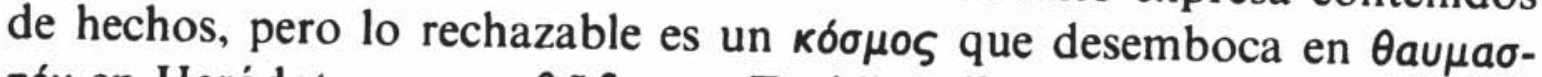
Tóv en Heródoto y en $\mu \nu \theta \tilde{\omega} \delta \varepsilon \varsigma$ en Tucídides ${ }^{47}$. Y cuando no se encuentra motivo para rechazarlo, se le cuelga, distanciándolo, de ese sintagma: "se dice, se cuenta" ${ }^{48}$. Tucídices, al hablar de los primeros habitantes de Sicilia, se ve obligado a hablar de los cíclopes y lestrígones, pero

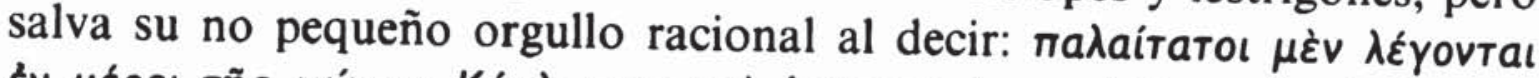

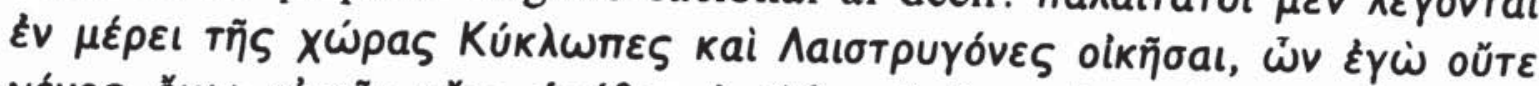

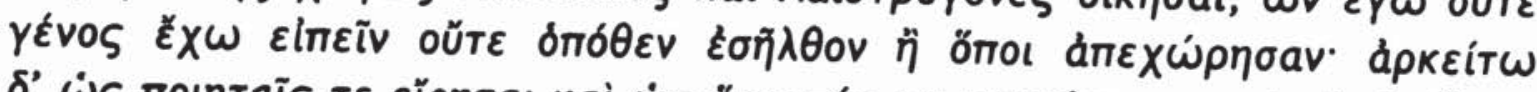

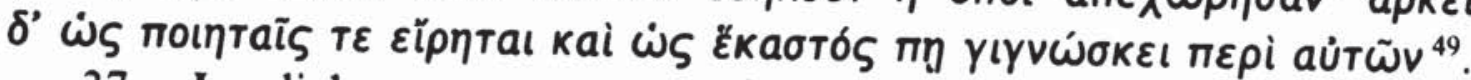

37. Lo dicho representa una función importante de la historiografia respecto al mito y, por lo demás, es la doctrina común. Sin embargo a mí me parece que la historiografia aportó algo más importante al mundo épico. Aportación que me cabe el pequeño orgullo de no encontrarla reflejada en los principales estudios al respecto. Me refiero al hecho de que la historiografia arranca al mundo épico un carácter histórico y de historicidad. Ya dijimos que el mundo épico constituía un pasado que, por su dimensión arcana y aislada, no explica el presente pero que, no obstante, su narración mítica rezuma hechos reales. Pues bien, y dejando a un lado a los logógrafos que en este contexto dicen muy poco o nada, Heródoto y Tucídides en sus respectivas introducciones se esfuerzan por tender un puente entre ese pasado mítico y el presente.

38. En efecto, Heródoto ${ }^{50}$ abre su obra diciendo que sus investigaciones tienen por objeto «que las grandes y maravillosas hazañas realizadas entre griegos y bárbaros no queden sin gloria». El propósito es claro: las luchas entre griegos y los no griegos de Asia Menor y Persia y, en concreto, las Guerras Médicas. Pero esta rivalidad no es de ahora. Es desde muy antiguo: la guerra de Troya, envuelta en la épica, es un antecedente muy claro. Mas, tal cual se encuentra en Homero, no es un pretérito del presente, donde no hay ni dioses ni héroes ${ }^{51}$. Y Heródoto convierte ese pretérito en una secuencia de episodios humanos y desa-

${ }^{47} \mathrm{Cf}$. aquí nota 45 .

${ }^{48} \mathrm{Cf}$. nota 42.

49 Th. VI 2. 1. "Los antiguos dicen que los Cíclopes y Lestrigones habitaron en una parte del país 'Sicilia', sobre lo que, por mi parte, ni puedo decir su estirpe, ni de dónde vinieron ni a dónde se retiraron. Baste el modo en que los poetas lo dicen y cómo cada uno conoce acerca de aquéllos.»

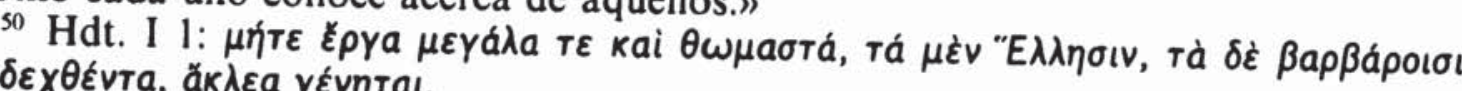

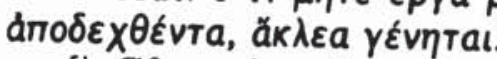

s1 $\mathrm{Cf}$. aquí parágr. 15 ss. 
cralizados, en una secuencia de raptos de mujeres que provocan esa hostilidad. Los fenicios primero raptan a Ío en uno de sus viajes comerciales $^{52}$. Aunque hija del rey fue con otras mujeres a curiosear al puerto. Después los griegos raptaron a Europa, la hija del rey de Tiro ${ }^{53}$. No quedó la cosa en paz. Y los griegos, que habían ido a la Cólquide y al río Fasis, se trajeron a Medea, cometiendo una nueva ofensa ${ }^{54}$. El rey de la Cólquide pidió satisfacción a los griegos, que no la dieron ${ }^{55}$. Y poco después Alejandro raptó a Helena, a lo que los griegos contestaron con una guerra abierta ${ }^{56}$. Y ello fue el inicio de que los asiáticos considerasen al mundo griego como enemigo. " "Los persas consideran" - dice Heródoto ${ }^{57}$ - que el raptar mujeres es fechoría de hombres injustos, pero el tomar con empeño la venganza de los raptos es de insensatos".

39. Se habrá observado que Heródoto habla de Ío, de los argonautas en el caso de Medea y de Helena. Son personajes míticos en Homero $\mathrm{y}$, sin embargo, aparecen como móviles normales de una incipiente rivalidad que caldea la gran hostilidad de las Guerras Médicas. El mundo épico se ha humanizado y puede explicar el presente de la guerra, objeto de su historia. Ha adquirido, pues, historicidad.

40. Con todo, el procedimiento de Heródoto no deja de ser bastante infantil. Pero es un procedimiento congruente con uno de sus mó-

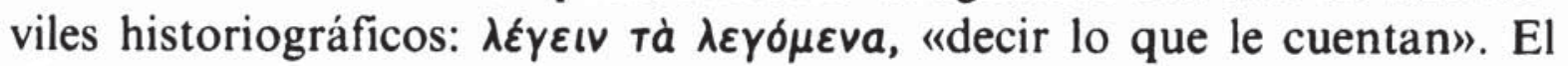
dice lo que le contaron los Persas. La historicidad que arranca al pasado mítico es una historicidad de estilo indirecto. No es producto de un análisis objetivo. En esto Tucídides le supera con mucho. Frente al $\lambda \dot{\varepsilon}-$

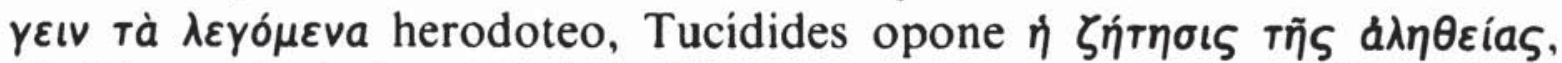
«la búsqueda de la verdad» ${ }^{58}$. Sintagma que se encuentra al final de lo que se ha llamado la "Arqueología» de Tucidides ${ }^{54}$. El término doxaıi入yía no se registra en Tucídides. Por primera vez se encuentra en Platón ${ }^{60}, y$ además definido. Viene a ser el espacio temporal en que se mezclan héroes y hombres y fundaciones de ciudades. En una palabra, el mundo mítico y épico.

\footnotetext{
52 Hdt. I 1.

53 Hdt. I 2.

${ }_{54} \mathrm{Hdt}$. I 2.

55 Hdt. I 3.

so Hdt. I 5.

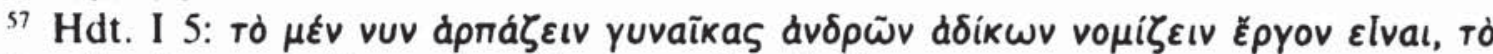

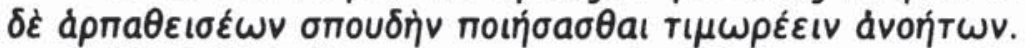

s\$ Th I 20,3. El texto muestra lo dificil que se vuelve esta búsqueda.

${ }^{54}$ Cf. aquí parágr. 41 y 42 .

60 Hipias Mayor $285 \mathrm{~d}$.
} 
41. Ahora bien, el nombre de Arqueología se aplica a los capítulos 2-22 del libro I y su contenido histórico abarca lo acontecido antes de la guerra del Peloponeso. Cierto es que Tucídides ya emplea el adjetivo naגaı́s en varias ocasiones, e incluso el verbo, aunque en el libro VII, ápxacoגoyeĩv ${ }^{61}$. Pero si hemos de estar concordes con la definición de Platón, que ápxaıodoyía es tiempo mítico y épico, la arqueologia tucididea sólo llegaría hasta el capítulo 11 . Esto es, lo que es anterior y contemporáneo a la guerra de Troya. El capítulo $12^{62}$ precisamente comienza así: «incluso después de la guerra de Troya, Grecia sufria todavía emigraciones... Aparte de que después de la guerra de Troya, ya no se habla de héroes ni de dioses que conviven con aquéllos", por lo que ya no es un mundo mítico, el método de investigación y de "búsqueda de la verdad" cambia radicalmente. Como sugiere Gomme ${ }^{63}$, quizá Tucídides se apoye ya en los relatos de los logógrafos y su análisis lo realice sobre noticias transmitidas. Mas sea lo que fuere, nuestro interés se centra en cómo concede historicidad a un mundo mítico $\mathrm{y}$, por consiguiente, la parte de la arqueología que hace al caso es lo que se dice en los once primeros capítulos.

42. Su método es de lo más sencillo, pero también de lo más objetivo: de lo que dice el mito, sólo puede decirse que es verdad, si hay indicios en el presente. Por tanto el presente, los indicios que observa a su alrededor conceden verdad al pasado, pero es éste el pasado el que, en la realidad de las cosas, da sentido al presente. Algunos ejemplos serán suficientes para comprender lo que intento significar. Del rey Minos dice ${ }^{64}$ que fue el más antiguo de los que formó una escuadra, alcanzó un poder sobre las islas vecinas y limpió de piratas el mar. Que hubo piratas y que éstos surgieron cuando empezaron a relacionarse por mar y que era un menester no vergonzoso es una suposición fundada: «esto queda claro todavía hoy, हैं que se glorian de practicarla bien". Ese sintagma हैं prueba que demuestra la suposición que el mito contiene. "También por

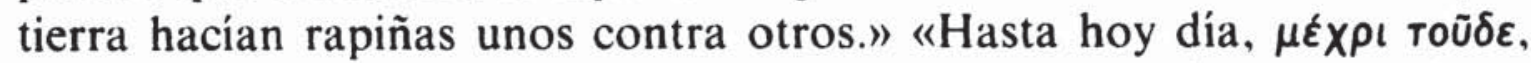

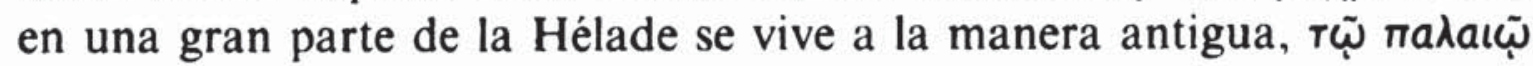
тро́пџ: entre los locros ozolos, los etolios, acarnienses y aquella parte

${ }_{61}$ Th. VII $69,2$.

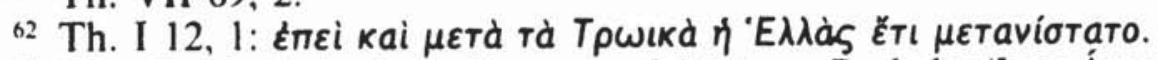

${ }^{63}$ The Greek Attitude to Poetry and History, Berkeley/Los Ángeles 1954, pp. 78, $92,117$.

${ }_{64}$ Th. I 4, 1.

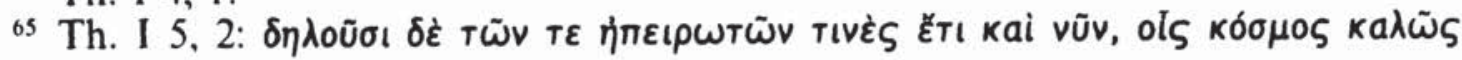
тоบ̃To $\delta \rho \tilde{v}$. 
del continente. $\mathrm{Y}$ les ha quedado como señal de aquella antigua vida de

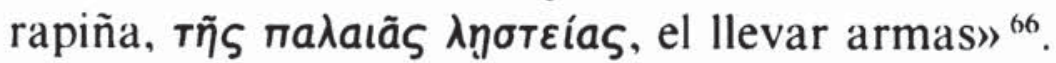

43. En otro lugar habla de que las ciudades fundadas más recientemente eran construidas en la costa y cerraban los istmos con murallas para protección. Pero las antiguas, ai maגaıai, tanto las continentales como las insulares, fueron construidas más lejos del mar a causa de la piratería. "Y hasta hoy todavía, $\mu \tilde{\varepsilon} \chi \rho \iota$ тоũ $\delta \varepsilon \tilde{\varepsilon} \tau \iota{ }^{67}$, están construidas en el interior.» $\mathrm{Y}$ para probar que los carios y fenicios también fueron piratas se apoya en las tumbas abiertas durante la guerra del Peloponeso en Delos: «más de la mitad - dice - resultaron ser carios, reconocidos por el tipo de armas y por el modo de enterramiento ${ }^{\text {tx }}$. Lo datos presentes demuestran el pasadon.

44. Otras veces y dejo esta enumeración de ejemplos respecto al contraste entre lo antiguo y el presente, éste no aparece de forma explícita pero sí contextual. El capítulo 9 comienza asi ${ }^{64}$ : "creo que Agamenón organizó la expedición porque era más poderoso que sus contemporáneos y no porque los pretendientes de Helena estuvieran obligados por el juramento prestado a Tindáreo". Aquí no hay un presente contrastivo, aparentemente. Pero sí hay toda una experiencia politica y económica de la guerra: la guerra del Peloponeso no es otra cosa que el enfrentamiento de dos poderes y es sabido que la teoría del poder como dinámica histórica es una constante en Tucídides. El presente, el ĚTı kai vúv, está en la propia teoría ${ }^{70}$.

45. Tucídides, por tanto, no rompe el hermetismo histórico de un mundo mítico, diciendo lo que otros le cuentan. Por el contrario, lo

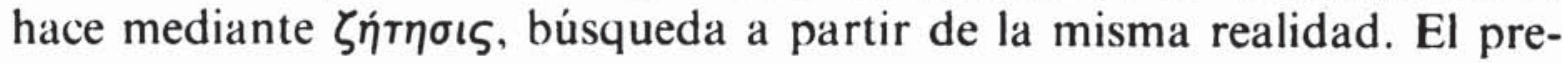
sente se torna herencia testimonial, $\tau \varepsilon \kappa \mu \eta \dot{\rho} \iota \mathrm{v}^{71}$, de un pretérito y éste se torna en causa de dicho presente. El aislamiento de un pasado mítico, que encierra hechos reales, brinda así su historicidad.

46. Y ya termino. El mito y, en concreto, el mito épico abre su mensaje a la historiografia. Pero no arrojó su cetro: sólo se lo prestó a la historiografia para que se apoyara en su camino. Y valga lo siguiente como conclusión: la historiografia nace a finales del siglo vi y principios del v. La mente griega, el voũs, pone en movimiento el logos en su doble vertiente: la lógica de la realidad, y la expresión de esa misma reali-

th Th. I 5, 30.

${ }^{67}$ Th. I 7, 1 .

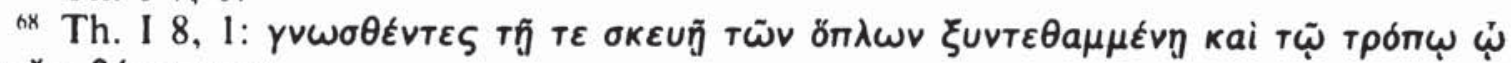
vũv हैं ڤ

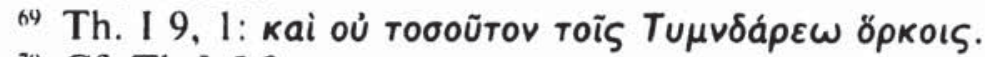

7) $\mathrm{Cf}$. Th I 5,2.

7 Ibidem. 
dad. El mito, entonces, se resquebraja: tiene mucho de lo que no es lógico, de ilógico, aberrante e incongruente pero también, en cuanto encierra hechos reales, tiene aspectos lógicos y de congruencia. El logos y sus cultivadores, los logógrafos, en esta dialéctica y diálogo, asumieron la congruencia lógica del mito y la incorporaron a la historicidad grie-

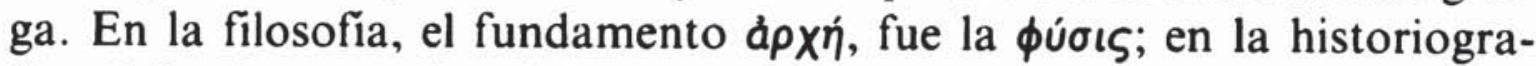
fia, el fundamento fue el logos. Porque el pasado sólo es operativo en el logos, en la narración.

A. Diaz-TEJera 